\title{
sciendo
}

\section{GENETIC VARIABILITY IN THE LOCI OF FABP4, PPAR $\gamma$ AND SCD GENES OF SHEEP BREEDS RAISED FOR DIFFERENT PURPOSES*}

\author{
Mirosław Kucharski, Urszula Kaczor ${ }^{1}$, Katarzyna Piórkowska² \\ ${ }^{1}$ Department of Animal Biotechnology, University of Agriculture in Krakow, ul. Rędzina 1B, \\ 30-274 Kraków, Poland \\ ${ }^{2}$ Department of Animal Molecular Biology, National Research Institute of Animal Production, \\ 32-083 Balice n. Kraków, Poland \\ •Corresponding author: miroslaw.kucharski@urk.edu.pl
}

\begin{abstract}
The present study was undertaken to analyse the genetic variation in coding sequences, splicing sites and regulatory sequences of $F A B P 4, P P A R \gamma$ and $S C D$ genes in five breeds of sheep raised in Poland with different purposes: meat (Suffolk, Ile de France), dairy/prolific (Olkuska sheep, Kołuda) and primitive breeds (Polish Mountain Sheep). To identify genetic variability HRM-PCR, sequencing and PCR-RFLP method were used. Determining the genetic structure of the mentioned genes revealed six SNPs: FABP4 - c. $73+13 \mathrm{~A}>\mathrm{T}$ and c.348 $+85 \mathrm{G}>\mathrm{A}, P P A R \gamma-\mathrm{c} .391-66 \mathrm{C}>\mathrm{T}$ $(c .481-66 \mathrm{C}>\mathrm{T})$ and $\mathrm{c.529}+27 \mathrm{G}>\mathrm{C}(\mathrm{c} .619+27 \mathrm{G}>\mathrm{C}), S C D-\mathrm{c} .{ }^{* 945 G}>\mathrm{A}$ and $\mathrm{c} . * 1116 \mathrm{~A}>\mathrm{G}$. For the c.*1116A>G SNP, a potential association with specific sheep body type and breeding purpose was found. In turn, the substitution c.*945G>A located in the regulatory region of the 3 '-UTR of the $O$ vis aries $S C D$ gene was identified for the first time. Based on the relationship demonstrated between sheep body constitution and productive type (dairy, meat) and the polymorphism of the $S C D$ gene, further research is needed. The correlation between $c$. $1116 \mathrm{~A}>\mathrm{G}$ polymorphism and growth rate, slaughter and carcass value as well as meat quality of lambs needs to be studied in more detail. Such studies may lead to more effective selection processes in sheep breeding in the future.
\end{abstract}

Key words: $F A B P 4, P P A R \gamma, S C D$, polymorphism, sheep

Taking into account present knowledge about the complete genome structure of Ovis aries, work on understanding the impact of breed on the genomic variation of individual genes still needs to be continued (Jiang et al., 2014).

In processes relating to fatty acid transformation in animal cells, proteins and the genes encoding them are directly or indirectly involved, including fatty acid binding protein 4 (FABP4), peroxisome proliferator-activated receptors gamma (PPAR $\gamma$ ), and stearoyl-CoA desaturase (SCD).

\footnotetext{
*Research funded by: DS-3242/KBZ/17.
} 
FABPs are intracellular proteins mainly responsible for binding and transporting long-chain fatty acids or related ligands, as well as for preventing damage to the cell structure due to the excessive accumulation of amphipathic fatty acid molecules (Mishkin et al., 1972; Ockner et al., 1972; Hanhoff et al., 2002). FABP4 is an isoform of the FABP protein family predominantly found in adipocytes and macrophages (Matarese and Bernlohr, 1988; Fu et al., 2000). FABP4 stimulates the expression of genes governing several metabolic processes as well as cell proliferation and differentiation (Zimmerman and Veerkamp, 2002). Thus far, all identified polymorphisms of the FABP4 gene in sheep were associated with production traits and meat quality, including mainly the level and composition of adipose tissue (Xu et al., 2011; Ibrahim et al., 2014).

PPARs are nuclear receptors belonging to the superfamily of steroid receptors and play an important role in regulating of gene transcription in pathways associated with e.g. metabolism or inflammation (Willson et al., 2000). Moreover, PPAR $\gamma$ receptors assume several important functions in the body. In the brain, PPAR $\gamma$ receptors are involved in differentiating nerve cells, reducing oxidative stress and have a positive effect on memory (Sobrado et al., 2009; Zhao et al., 2011; Barbiero et al., 2014; Pisanu et al., 2014). In skeletal muscles, PPARs are responsible for the increase in fatty acid oxidation, whereas in the small intestine - for reducing inflammation (Barak et al., 1999; Rosen et al., 1999; Kersten et al., 1999; Koutnikova et al., 2003; Ferre, 2004). In contrast, they are engaged in adipocyte differentiation, triglyceride synthesis and an increase in insulin sensitivity in the adipose tissue (Tontonoz et al., 1994; Ferre, 2004; Marion-Letellier et al., 2015). There is a lack of papers identifying genetic variability of $P P A R \gamma$ gene in sheep. In cattle, there were detected few polymorphisms associated with amino acid replacement and meat quality (Fan et al., 2011, 2012). Some relationship between PPAR $\gamma$ polymorphism and MUFA n-3 content in adipose tissue was found (Sevane et al., 2013).

Stearoyl-CoA desaturase ( $\Delta 9$-desaturase) is an enzyme [EC 1.14.19.1] of the oxidoreductases class catalyzing the synthesis of PUFA (polyunsaturated fatty acids). It catalyzes the transformation of saturated acids - palmitic (C16:0) and stearic (C18:0) - into MUFA (monounsaturated fatty acids) palmitoleic acid (C16:1 n-7) and oleic acid (C18:1 n-9), respectively. Stearoyl-CoA desaturase is also needed in the synthesis of conjugated linoleic acid (the cis-9, trans-11 isomer of CLA) from oleic acid (trans-11 C18:1) (Enoch et al., 1976; Corl et al., 2001). Changes in the activity of the SCD protein can be caused by several factors such as a poorly balanced diet, liver disease or hormonal balance disruptions and result in an increase or decrease in liver MUFA content (Ntambi et al., 2004; Karahashi et al., 2013). In addition, SCD is involved in the formation of triacylglycerols, regulation of insulin sensitivity, and processes relating to ER stress or VLDL secretion (Dixon et al., 1991; Legrand et al., 1997; Miyazaki et al., 2000; Gutiérrez-Juárez et al., 2006; Wei et al., 2006; Cao et al., 2008; Wei et al., 2009; Ariyama et al., 2010). The few studies performed so far on the genetic variability of the $S C D$ gene of sheep suggest that mutations of this gene are responsible for the fatty acid profile in the milk of these animals (Bernard et al., 2001; García-Fernández et al., 2009). 
The aim of this study was to investigate the genetic variability in the regions of coding and regulatory sequences and splice sites of the FABP4, PPAR $\mathrm{y}$ and SCD genes in five Polish sheep breeds raised for various purposes. Meat breeds of sheep, such as Suffolk and Ile de France, have a strong body constitution including high muscle mass and high body fat content. These imported breeds have superior meat quality and lambs are characterized by a fast growth rate. Body weight should be at least $100-125 \mathrm{~kg}$ for rams and $60-80 \mathrm{~kg}$ for ewes of Ile de France. Body weight for Suffolk rams and ewes is $110-130 \mathrm{~kg}$ and $65-90 \mathrm{~kg}$, respectively. The primitive, triple-purpose Polish Mountain Sheep breed is bred in the mountains and foothills of the Polish Carpathians; these animals are finely built, with weak musculature and low body fat. Body weight should be at least 50-60 kg for rams and 45-55 kg for ewes. Two dairy/prolific breeds - the Kołuda and Olkuska sheep breeds, with a mixed body composition, were also chosen for the experiment. They are two native Polish breeds characterized by high fertility $-200 \%$. Body weight should be at least 80-100 kg for rams and 60-75 kg for ewes of Kołuda, and about 50-60 kg for rams and ewes of Olkuska sheep. (Niżnikowski, 2011).

\section{Material and methods}

\section{Experimental animals}

One hundred and fifty unrelated animals (ewes) aged 2-3 years, belonging to five breeds of various types: Kołuda sheep, the prolific dairy Olkuska sheep, Polish Mountain Sheep, Ile de France and Suffolk (n for each breed = 30) were selected for the study. The animals were kept at the Experimental Station of the Department of Animal Biotechnology of the University of Agriculture in Kraków and at private sheep farms in southern and central Poland.

\section{Sample and DNA sources}

Peripheral blood $(5 \mathrm{ml})$ was collected from the external jugular vein into tubes with $\mathrm{K}_{3}$ EDTA anticoagulant (Sarstead, Stare Babice, Poland). Genomic DNA isolation was performed using the MasterPure ${ }^{\mathrm{TM}}$ DNA Purification Kit for Blood Version II (Epicentre, an Illumina Company, Madison, USA). The quality of the isolates was estimated by electrophoresis with $1 \%$ agarose gel using the Agarose BioReagent, for molecular biology, low EEO (Sigma Aldrich, Saint Louis, Missouri, USA) and a $0.5 \times$ TBE (Tris-borate-EDTA) buffer; the Mupid-One ${ }^{\mathrm{TM}}$ Complete Agarose Gel Electrophoresis System (Abo, Gdańsk, Poland) was employed. The quality was also assessed spectrophotometrically using the NanoDrop 2000c by Thermo Fisher Scientific (Waltham, Massachusetts, USA).

\section{High resolution melting polymerase chain reaction analysis}

Analysis of genetic variability in the studied loci was performed with HRMPCR (high resolution melting polymerase chain reaction) analysis method using the KAPA HRM FAST PCR Kit (Kapa Biosystems, Wilmington, Massachusetts, 
USA). The analysis was performed for 18 exons of the FABP4, PPAR $\gamma$ and SCD genes. For the reaction, 23 pairs of primers were designed using the Primer3plus program (http://primer3plus.com/) (Table 1). The primers were designed based on gene sequences found in the National Center for Biotechnology Information database (NCBI, http://www.ncbi.nlm.nih.gov/): NC_019466.2 (FABP4), NC_019476.2 (PPAR $)$, FJ513370.1 (SCD). HRM-PCR was performed for each of the 23 designed fragments according to the developed protocols on 50 randomly selected individuals (10 ewes per breed) using the Real-Time PCR System Eco ${ }^{\mathrm{TM}}$ (Illumina Company, Madison, USA).

Table 1. Sequences of primers designed to perform HRM analysis for the FABP4, PPAR $\gamma$ and $S C D$ genes

\begin{tabular}{|c|c|c|c|}
\hline $\begin{array}{c}\text { Name of the gene/ } \\
\text { fragment }\end{array}$ & Primers sequences & Location & $\begin{array}{c}\text { Product } \\
\text { size } \\
\text { (bp) }\end{array}$ \\
\hline 1 & 2 & 3 & 4 \\
\hline \multicolumn{4}{|l|}{ FABP4 } \\
\hline \multirow[t]{2}{*}{ FABP4-1 } & F: 5'-GCTGCACTTCTTTCTCATCTTG-3' & 5'-UTR, exon 1 & 145 \\
\hline & R: 5'-GCTGCACTTCTTTCTCATCTTG-3' & & \\
\hline \multirow[t]{2}{*}{ FABP4-2 } & F: 5'-TTCCCATCTATAGTGTGGGCTTT-3' & Exon 2 & 210 \\
\hline & R: 5'-TCTGCTCCAGTTCTTTATTCCTC-3' & & \\
\hline \multirow[t]{2}{*}{ FABP4-3 } & F: 5'-AATCACTTTTAATTATCCCCACAGA-3' & Exon 3 & 140 \\
\hline & R: 5'-CAGAAGATACTCACCAGCACCA-3' & & \\
\hline \multirow[t]{2}{*}{ FABP4-4 } & F: 5’-GCCTTTGTGCCTAGGAATGT-3' & Exon 4, 3'-UTR & 111 \\
\hline & R: 5'-GTCATGGAGTTCGATGCAAA-3' & & \\
\hline \multicolumn{4}{|l|}{$P P A R \gamma$} \\
\hline \multirow[t]{2}{*}{$\operatorname{PPAR} \gamma-1$} & F: 5'-AАAАATCTTCTTTCTTTTCAGTTGTTC-3' & 5'-UTR, exon 1 & 118 \\
\hline & R: 5'-CCTACCGTTCAGGAGTGACA-3' & & \\
\hline \multirow[t]{2}{*}{$\operatorname{PPAR} \gamma-2$} & F: 5'-CAGCTGGCCTTTTCTCTGTT-3' & Exon 2 & 260 \\
\hline & R: 5'-CCACATACTTTGGTACTCTTGGA-3' & & \\
\hline \multirow[t]{2}{*}{$\operatorname{PPAR} \gamma-3$} & F: 5'-CACAGGTGCAATCAAAGTGG-3' & Exon 3 & 172 \\
\hline & R: 5'-GCATCCTTCACAAGCATGAA-3' & & \\
\hline \multirow[t]{2}{*}{$\operatorname{PPAR} \gamma-4$} & F: 5’-CCCCATATTCCTTTGTAGGG-3’' & Exon 4 & 176 \\
\hline & R: 5'-CCACGAAGTGCTCACTTACCA-3' & & \\
\hline \multirow[t]{2}{*}{$\operatorname{PPAR} \gamma-5$} & F: 5’-CATCCCACCСТTTTCTTCTG-3' & Exon 5 & 233 \\
\hline & R: 5'-GAGAACTAACTGATTTGTCTGTCGTC-3' & & \\
\hline \multirow[t]{2}{*}{$\operatorname{PPAR} \gamma-6$} & F: 5'-TTCTCCCATTTTTCTTTGCAG-3' & Exon 6 & 281 \\
\hline & R: 5'-GAGGCCAGCATCGTGTAAAT-3' & & \\
\hline \multirow[t]{2}{*}{$\operatorname{PPAR} \gamma-7$} & F: 5’-AAGAATATCCCCGGCTTTGT-3' & Exon 6 & 309 \\
\hline & R: 5'-GAAAACCGCAAGCAGCAG-3' & & \\
\hline \multirow[t]{2}{*}{$\operatorname{PPAR} \gamma-8$} & F: 5’-GTCTTCCGTTTCTGCTCTCC-3' & Exon 7, 3'-UTR & 305 \\
\hline & R: 5'-AGGAAGATGTCGCCAGTGAG-3' & & \\
\hline
\end{tabular}


Table 1 - contd.

\begin{tabular}{|c|c|c|c|}
\hline 1 & 2 & 3 & 4 \\
\hline \multicolumn{4}{|l|}{$S C D$} \\
\hline \multirow[t]{2}{*}{ SCD-1 } & F: 5'-CTTTAAATCCCCAGCACAGC-3' & 5'-UTR, exon 1 & 258 \\
\hline & R: 5'-GGCCATTACTCGGAAGCTCT-3' & & \\
\hline \multirow[t]{2}{*}{ SCD-2 } & F: 5'-ССТССАСТТССТСТСССТТС-3' & Exon 2 & 329 \\
\hline & R: 5'-GGGAGGACATGGGAACTTCT-3' & & \\
\hline \multirow[t]{2}{*}{ SCD-3 } & F: 5'-CCCTGTCTTATCCTGGCAGT-3' & Exon 3 & 170 \\
\hline & R: 5'-GAGCACAGCTGGCTTCTCAC-3' & & \\
\hline \multirow[t]{2}{*}{ SCD-4 } & F: 5'-TCATTCCTCTTCTCTGTTCCTCT-3' & Exon 4 & 256 \\
\hline & R: 5'-CCAGCTCCATCATCATGTCA-3' & & \\
\hline \multirow[t]{2}{*}{ SCD-5 } & F: 5'-TGAGCGTATGATCTCTCAATGC-3' & Exon 5 & 281 \\
\hline & R: 5'-TCTTGCTGTGGACTGCTGAC-3' & & \\
\hline \multirow[t]{2}{*}{ SCD-6 } & F: 5'-AACTTTTCTCTGCTTTTGTTCCA-3' & Exon 6 & 257 \\
\hline & R: 5'-GCTTTTGGAAAAGGAATCCA-3' & & \\
\hline \multirow[t]{2}{*}{ SCD-7 } & F: 5'-GCTGAGTTTCTGGTCCCTTG-3' & Exon 6 & 341 \\
\hline & R: 5'-TAGGCTTTGGAAGCTGGAAA-3' & & \\
\hline \multirow[t]{2}{*}{ SCD-8 } & F: 5'-AAGGCAAGCAGTTGGTCAGT-3' & Exon 6 & 277 \\
\hline & R: 5'-ATGCTGACTCTCTCCCCTGA-3' & & \\
\hline \multirow[t]{2}{*}{ SCD-9 } & F: 5'-GCACCAAACTGCAAAAACAG-3' & Exon 6 & 290 \\
\hline & R: 5'-CTGCAGCAGAGACCACTTTT-3' & & \\
\hline \multirow[t]{2}{*}{ SCD-10 } & F: 5'-GGCTGAGGATAAAGAAGAAGCA-3' & Exon 6 & 284 \\
\hline & R: 5'-ACCATACCACCAACGCATCT-3' & & \\
\hline \multirow[t]{2}{*}{ SCD-11 } & F: 5'-AGATGCGTTGGTGGTATGGT-3' & Exon 6, 3'-UTR & 304 \\
\hline & R: 5'-TCCCCCAGCAATGTAATCTC-3' & & \\
\hline
\end{tabular}

\section{Sequencing}

The samples for which the resulting melt curves differed as well as controls for the detected polymorphic sites were sequenced. For this purpose, 13 primer pairs were designed using the Primer3plus program (http://primer3plus.com/) (Table 2).

Sequential PCR amplifications were performed for both the forward and the reverse primers from each primer pair (Table 2) using the BigDye ${ }^{\circledR}$ XTerminator ${ }^{\mathrm{TM}}$ kit (Applied Biosystems, Thermo Fisher Scientific, Waltham, Massachusetts, USA) according to the manufacturer's protocol.

The obtained PCRseq reaction products were purified with the use of the BigDye ${ }^{\circledR}$ XTerminator ${ }^{\mathrm{TM}}$ Purification Kit (Applied Biosystems, Thermo Fisher Scientific, Waltham, Massachusetts, USA) as recommended by the manufacturer and sequenced using the ABI $3130 \mathrm{XL}$ device (Applied Biosystems, Thermo Fisher Scientific, Waltham, Massachusetts, USA). Analysis of the obtained sequences was performed using the FinchTV chromatogram viewer (Geospiza, Seattle, USA). 


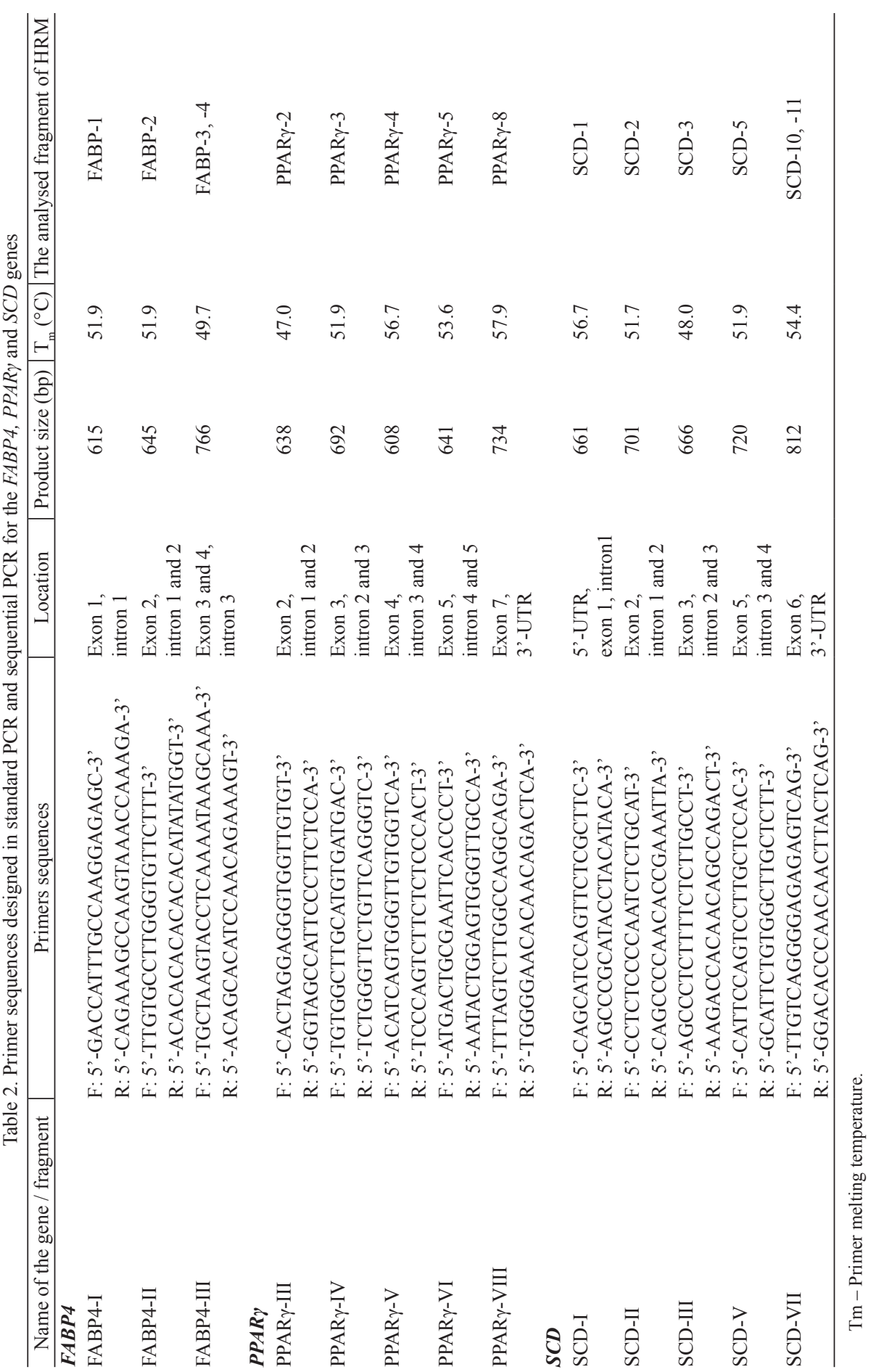




\section{PCR-restriction fragment length polymorphism (PCR-RFLP)}

The PCR-RFLP method was used for the genotyping of identified mutations in the entire population of experimental animals. To identify individual polymorphic changes by RFLP, the restriction enzymes $\mathrm{BccI}, \mathrm{HpHI}$, HpyCH4III, HpyCH4V, RsaI (Thermo Fisher Scientific, Waltham, Massachusetts, USA) were selected using the NEBcutter V2.0 program (New England Biolabs, Ipswich, Massachusetts, USA). Table 3 contains information on the restriction enzymes used in the PCR-RFLP reaction.

Table 3. Restriction enzymes used in the PCR-RFLP reaction

\begin{tabular}{l|c|c}
\hline \multicolumn{1}{c|}{ Restriction enzyme } & Temperature/Incubation time & Enzyme digested fragment \\
\hline HpyCH4V & $37^{\circ} \mathrm{C} / 1 \mathrm{~h}$ & FABP4-I \\
$H p H \mathrm{I}$ & $37^{\circ} \mathrm{C} / 1 \mathrm{~h}$ & FABP4-III \\
$B c c \mathrm{I}$ & $37^{\circ} \mathrm{C} / 1 \mathrm{~h}$ & PPAR $\gamma-\mathrm{V}$ \\
$H p y C H 4 \mathrm{III}$ & $37^{\circ} \mathrm{C} / 1 \mathrm{~h}$ & PPAR $\gamma-\mathrm{V}$ \\
BccI & $37^{\circ} \mathrm{C} / 1 \mathrm{~h}$ & SCD-VII \\
RsaI & $37^{\circ} \mathrm{C} / 1 \mathrm{~h}$ & SCD-VII \\
\hline
\end{tabular}

After PCR-RFLP, electrophoretic separation (120 V, $120 \mathrm{~min})$ of the digested fragments was performed with 3.5\% agarose gel using the Agarose BioReagent, for molecular biology, low EEO (Sigma Aldrich, Saint Louis, Missouri, USA) and the marker Gene Ruler 50 bp DNA Ladder \#SM0371 (Fermentas, Thermo Fisher Scientific, Waltham, Massachusetts, USA).

\section{Statistical analysis}

POPGENE software (Yeh and Boyle, 1997) was used to analyse the allele and genotype frequency and differences between breeds for each of the identified mutations. The chi-square conformity test (Pearson's test) was applied to verify whether each of the examined sheep breed populations was in Hardy-Weinberg equilibrium in the analysed loci, using Statistica ver. 10 (StatSoft Inc., Tulsa, USA).

\section{Results}

Six SNPs were identified in the regions of coding and regulatory sequences and splice sites of the FABP4, PPAR $\gamma$ and $S C D$ genes where the possible connection between the $\mathrm{c} .{ }^{*} 1116 \mathrm{~A}>\mathrm{G}$ polymorphism and sheep body and usage type was shown.

The screening for polymorphism in the FABP4 gene by the HRM method revealed the presence of four polymorphic sites in the regions of fragments limited by the primers: FABP4-1, FABP4-2, FABP4-3, FABP4-4. The sequencing of PCR fragments of the FABP4 gene selected in the HRM reaction and representing different polymorphic variants and their comparison with the sequences found in the NCBI database allowed us to identify the mutations c. $73+13 \mathrm{~A}>\mathrm{T}(\mathrm{g} .57540957 \mathrm{~T}>\mathrm{A}$, 
rs404716304) and c.348 + 85G $>$ A (g.57536954C $>$ T, rs422473198). The transition c. $73+13 \mathrm{~A}>\mathrm{T}$ was in intron 1 . Following digestion with the $H p y C H 4 \mathrm{~V}$ enzyme, 3 genotypes were identified: AA, TT and AT (Figure 1). The frequency of alleles and of genotypes for each studied breed is shown in Table 4 . The presence of the c.73 $+13 \mathrm{~A}>\mathrm{T}$ mutation was demonstrated in all sheep breeds tested, except for the Ile de France meat breed. The highest frequency of the T allele $(0.47)$ was found in the Suffolk breed; TT homozygotes were identified for this breed only, constituting as much as $22 \%$ of the total population. At the same time, the Suffolk breed was also found to have a high frequency of the AT genotype (0.50). In the other breeds, a high frequency of the A allele was observed. Higher frequencies of the AA homozygotes in the examined locus - in comparison to those noted for the Suffolk and Polish Mountain Sheep breeds - were found in the breeds with mixed meat/dairy body constitution $(\mathrm{P}<0.01)$. The studied breed populations were shown to be in HardyWeinberg equilibrium (HWE) in the analysed locus.

Table 4. Alleles and genotypes frequency at the locus c. $73+13 \mathrm{~A}>\mathrm{T}$

\begin{tabular}{l|c|c|c|c|c|c|c}
\hline \multirow{2}{*}{ Breed } & \multicolumn{7}{c}{ Alleles and genotypes frequency } \\
\cline { 2 - 9 } & Allele A & Allele T & AA & AT & TT & $\chi^{2}$ & P-value \\
\hline Ile de France & 1.00 & - & 1.00 & - & - & 0.00 & - \\
Suffolk & 0.53 & 0.47 & 0.28 & 0.50 & 0.22 & 0.14 & 0.70 \\
Kołuda sheep & 0.98 & 0.02 & 0.96 & 0.04 & - & 0.03 & 0.93 \\
Olkuska sheep & 0.97 & 0.03 & 0.94 & 0.06 & - & 0.02 & 0.85 \\
Polish Mountain Sheep & 0.80 & 0.20 & 0.66 & 0.34 & - & 0.48 & 0.17 \\
Population (n=150) & 0.86 & 0.14 & 0.74 & 0.24 & 0.02 & - & - \\
\hline
\end{tabular}

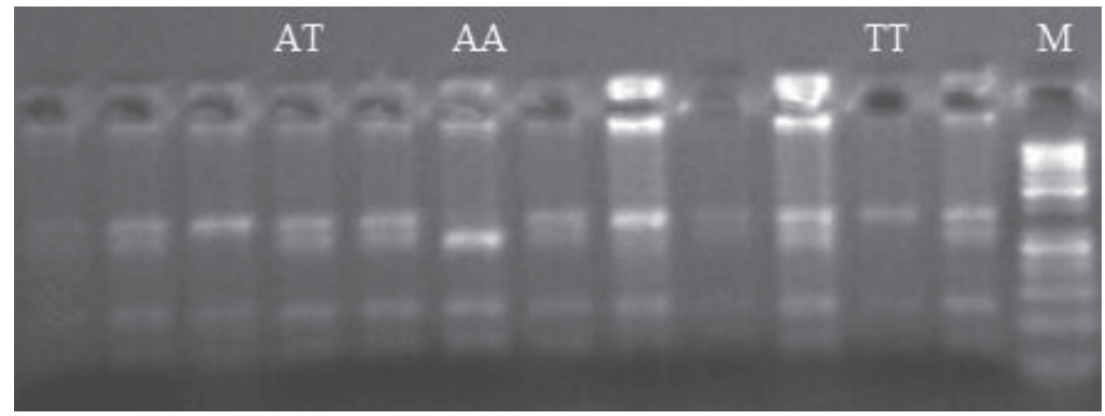

M - Gene Ruler 50 bp DNA Ladder \#SM0371 (Fermentas, Thermo Fisher Scientific, Waltham, Massachusetts, USA).

AA genotype - fragments sized 54, 66, 74, 129, 292 bp.

AT genotype - fragments sized 54, 66, 74, 129, 292, 366 bp.

TT genotype - fragments sized of 54, 66, 129, $366 \mathrm{bp}$.

Figure 1. Electrophoregram of digestion of 615 bp PCR product (FABP4-I) with the HpyCH4V enzyme 
A substitution in intron 3 of the FABP4 gene - namely c.348 $+85 \mathrm{G}>\mathrm{A}$ (g.57536954C $>$ T, rs422473198) - was identified with the use of the HpHI restriction enzyme. The image of the genotypes for the c. $348+85 \mathrm{G}>\mathrm{A}$ mutation is shown in Figure 2. Table 5 shows the frequencies of individual alleles and genotypes for each of the sheep breeds. The mutation c. $348+85 \mathrm{G}>\mathrm{A}$ was identified in Koluda and Olkuska ewes, as well as in the Polish Mountain Sheep and Suffolk breeds. The Ile de France meat breed turned out to be monomorphic, i.e. all ewes were of the GG genotype. In contrast, the GG and GA genotypes were identified in the Koluda and Olkuska sheep breeds. A high frequency of the G allele was observed in all breeds, and a $48 \%$ share of the A allele was recorded for Suffolk ewes only. In animals of the Suffolk and Polish Mountain Sheep breeds, heterozygote frequency was 50\% and $30 \%$ respectively, with the frequency of AA homozygotes recorded at $23 \%$ and $3 \%$ respectively. With respect to the tested locus, the Polish Mountain Sheep population demonstrated statistical significance for departure from the HWE equilibrium.

Table 5. Alleles and genotypes frequency at the locus c. $348+85 \mathrm{G}>\mathrm{A}$

\begin{tabular}{l|c|c|c|c|c|c|c}
\hline \multirow{2}{*}{\multicolumn{1}{c}{ Breed }} & \multicolumn{7}{c}{ Alleles and genotypes frequency } \\
\cline { 2 - 8 } & Allele G & Allele A & GG & GA & AA & $\chi^{2}$ & P-value \\
\hline Ile de France & 1.00 & - & 1.00 & - & - & 0.00 & - \\
Suffolk & 0.52 & 0.48 & 0.27 & 0.50 & 0.23 & 0.53 & 0.46 \\
Kołuda sheep & 0.98 & 0.02 & 0.96 & 0.04 & - & 0.03 & 0.93 \\
Olkuska sheep & 0.93 & 0.07 & 0.87 & 0.13 & - & 0.15 & 0.70 \\
Polish Mountain Sheep & 0.82 & 0.18 & 0.67 & 0.30 & 0.03 & 6.86 & 0.02 \\
Population (n=150) & 0.85 & 0.15 & 0.72 & 0.26 & 0.02 & - & - \\
\hline
\end{tabular}

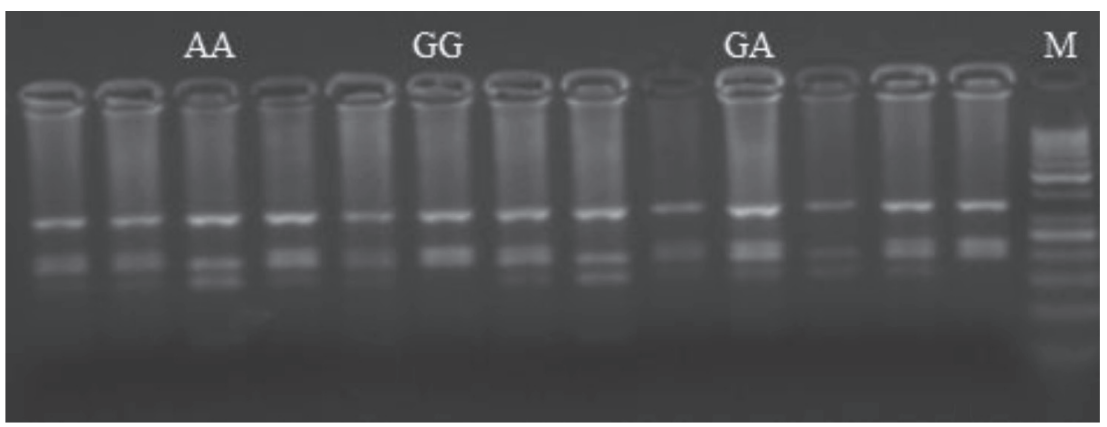

M - Gene Ruler 50 bp DNA Ladder \#SM0371 (Fermentas, Thermo Fisher Scientific, Waltham, Massachusetts, USA).

genotype GG - fragments of size 199, 224, 339 bp.

genotype GA - fragments of size 6, 161, 199, 224, 339 bp.

genotype AA - fragments of size $6,161,199,339 \mathrm{bp}$.

Figure 2. Electrophoregram of digestion of 766 bp PCR product (FABP4-III) with the HpHI enzyme 
The HRM reaction conducted in eight fragments of the PPAR gene showed the existence of five polymorphic sites in which only two substitutions were confirmed in the sequencing reaction. The g.56587277G $>$ A (rs414209574) mutation identified in intron 3 was also described as c.391-66C $>$ T for the $P P A R G-201$ transcript and as c.481-66C $>$ T for the PPARG-202 transcript. When identifying polymorphic changes in the five sheep breeds using the $B c c I$ restriction enzyme, the fragment (PPAR $\gamma-\mathrm{V}$ ) of $608 \mathrm{bp}$ was digested into two fragments, 181 and $427 \mathrm{bp}$ respectively, for CC homozygous individuals (Figure 3 ). In contrast, the substitution in the $\mathrm{C}>\mathrm{T}$ sequence resulted in the loss of the restriction site for this enzyme, thus, after electrophoretic separation, giving a single, non-digested product (608 bp) for TT genotype animals. The allele and genotype distribution identified in individual breeds for the c.39166C $>\mathrm{T}$ (c.481-66C $>\mathrm{T})$ mutation are shown in Table 6. All sheep breeds showed a high frequency of the $\mathrm{T}$ allele. The $\mathrm{C}$ allele was present with a high frequency $(0.35)$ in the Ile de France ewes; the presence of CC homozygotes (12\%) and a high frequency of heterozygotes $(46 \%)$. Only individuals with the TT genotype have been observed in the Kołuda and Olkuska sheep breeds. The populations of Ile de France, Polish Mountain Sheep and Suffolk sheep were in Hardy-Weinberg equilibrium in the locus c.391-66C $>$ T.

Table 6. Alleles and genotypes frequency at the locus c.391-66C $>$ T $(c .481-66 \mathrm{C}>\mathrm{T})$

\begin{tabular}{l|c|c|c|c|c|c|c}
\hline \multirow{2}{*}{ Breed } & \multicolumn{7}{c}{ Alleles and genotypes frequency } \\
\cline { 2 - 8 } & Allele C & Allele T & CC & CT & TT & $\chi^{2}$ & P-value \\
\hline Ile de France & 0.35 & 0.65 & 0.12 & 0.46 & 0.42 & 0.10 & 0.79 \\
Suffolk & 0.02 & 0.98 & - & 0.04 & 0.96 & 0.03 & 0.93 \\
Kołuda sheep & - & 1.00 & - & - & 1.00 & 0.00 & - \\
Olkuska sheep & - & 1.00 & - & - & 1.00 & 0.00 & - \\
Polish Mountain Sheep & 0.12 & 0.88 & - & 0.21 & 0.79 & 0.53 & 0.47 \\
Population (n=150) & 0.10 & 0.90 & 0.01 & 0.18 & 0.81 & - & - \\
\hline
\end{tabular}

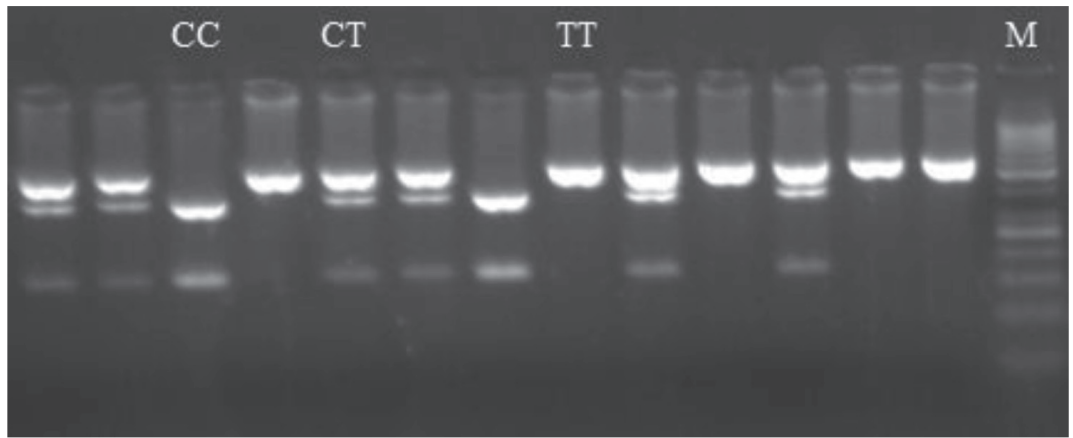

M - Gene Ruler 50 bp DNA Ladder \#SM0371 (Fermentas, Thermo Fisher Scientific, Waltham, Massachusetts, USA).

CC genotype - fragments of size $181,427 \mathrm{bp}$.

CT genotype - fragments of size $181,427,608 \mathrm{bp}$.

TT genotype - fragment of $608 \mathrm{bp}$ in size.

Figure 3. Electrophoregram of digestion of $608 \mathrm{bp}$ PCR product (PPAR $\gamma-\mathrm{V})$ with the $B c c I$ enzyme 
The mutation identified in the PPAR $\gamma$ gene: g.56587046C $>$ G (PPARG-201 c. $529+27 \mathrm{G}>\mathrm{C}$, PPARG-202 c. $619+27 \mathrm{G}>\mathrm{C}$, rs408428244) is the guanine transversion to cytosine in intron 4 . The electrophoregram of genotypes identified with the use of the HpyCH4III enzyme is presented in Figure 4. Table 7 shows the allele frequencies for the mutation c. $529+27 \mathrm{G}>\mathrm{C}(\mathrm{c} .619+27 \mathrm{G}>\mathrm{C})$ in the PPAR gene. A high frequency of the $\mathrm{C}$ allele was identified in all breeds. The Kołuda and Olkuska sheep breeds turned out to be monomorphic (CC genotype). All three genotypes were found only in the Ile de France breed, in which the frequency of the G allele was shown at $35 \%$. The highest frequency of GC heterozygotes $-46 \%$ - was noted for the same breed, while the lowest frequency was recorded in Suffolk ewes, the other meat breed studied (4\%). The populations of Ile de France, Suffolk and Polish Mountain Sheep ewes were in genetic Hardy-Weinberg equilibrium in the studied locus.

Table 7. Alleles and genotypes frequency at the locus c. $529+27 \mathrm{G}>\mathrm{C}(\mathrm{c} .619+27 \mathrm{G}>\mathrm{C})$

\begin{tabular}{l|c|c|c|c|c|c|c}
\hline \multirow{2}{*}{\multicolumn{1}{c}{ Breed }} & \multicolumn{7}{c}{ Alleles and genotypes frequency } \\
\cline { 2 - 8 } & Allele G & Allele C & GG & GC & CC & $\chi^{2}$ & P-value \\
\hline Ile de France & 0.35 & 0.65 & 0.12 & 0.46 & 0.42 & 0.14 & 0.79 \\
Suffolk & 0.02 & 0.98 & - & 0.04 & 0.96 & 0.03 & 0.93 \\
Kołuda sheep & - & 1.00 & - & - & 1.00 & 0.00 & - \\
Olkuska sheep & - & 1.00 & - & - & 1.00 & 0.00 & - \\
Polish Mountain Sheep & 0.12 & 0.88 & - & 0.23 & 0.77 & 0.53 & 0.47 \\
Population (n=150) & 0.10 & 0.90 & 0.01 & 0.18 & 0.81 & - & - \\
\hline
\end{tabular}

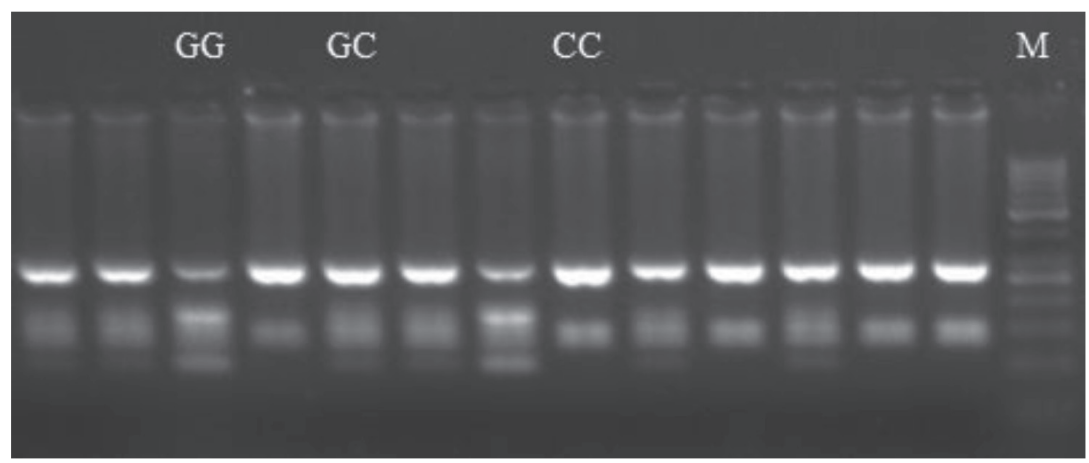

M - Gene Ruler 50 bp DNA Ladder \#SM0371 (Fermentas, Thermo Fisher Scientific, Waltham, Massachusetts, USA).

genotype GG - fragments sized 19, 107, 140, 160, $182 \mathrm{bp}$.

genotype GC - fragments sized 19, 107, 140, 160, 182, $289 \mathrm{bp}$.

genotype CC - fragments sized 140, 160. 289 bp.

Figure 4. Electrophoregram of digestion of $608 \mathrm{bp} \mathrm{PCR} \mathrm{product} \mathrm{(PPAR} \gamma-\mathrm{V}$ ) with the HpyCH4III enzyme 
In the case of the $S C D$ gene, the presence of the transition c. $* 945 \mathrm{G}>\mathrm{A}$ (g.20442503C $>$ T) identified in the 3'-UTR region was tested with the BccI enzyme (Figure 5). As a result of the performed analysis, only one individual with the genotype GA (a heterozygote) was identified. No AA genotype animals were found among the studied breeds. The distribution of individual alleles and genotypes is shown in Table 8.

Table 8. Alleles and genotypes frequency at the locus c. $* 945 \mathrm{G}>\mathrm{A}$

\begin{tabular}{l|c|c|c|c|c|c|c}
\hline \multirow{2}{*}{ Breed } & \multicolumn{7}{c}{ Alleles and genotypes frequency } \\
\cline { 2 - 8 } & Allele G & Allele A & GG & GA & AA & $\chi^{2}$ & P-value \\
\hline Ile de France & 1.00 & - & 1.00 & - & - & 0.00 & - \\
Suffolk & 0.98 & 0.02 & 0.96 & 0.04 & - & 0.03 & 0.93 \\
Kołuda sheep & 1.00 & - & 1.00 & - & - & 0.00 & - \\
Olkuska sheep & 1.00 & - & 1.00 & - & - & 0.00 & - \\
Polish Mountain Sheep & 1.00 & - & 1.00 & - & - & 0.00 & - \\
Population (n=150) & 0.99 & 0.01 & 0.98 & 0.02 & - & - & - \\
\hline
\end{tabular}

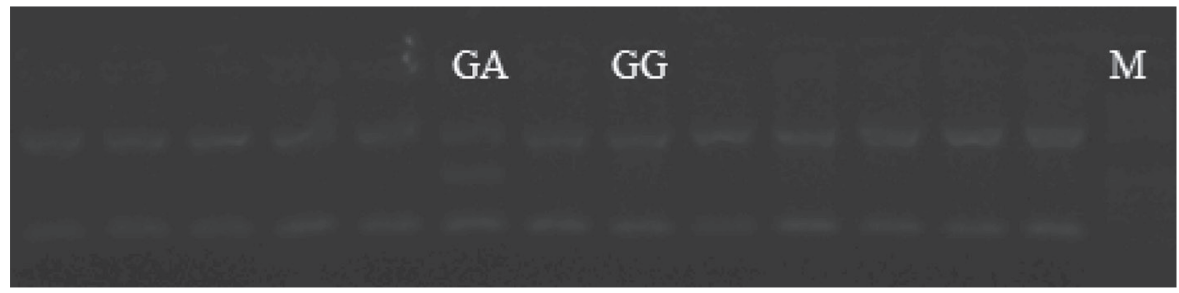

M - Gene Ruler 50 bp DNA Ladder \#SM0371 (Fermentas, Thermo Fisher Scientific, Waltham, Massachusetts, USA).

GG genotype - fragments sized 115, 125, $572 \mathrm{bp}$.

GA genotype - fragments sized 115, 125, 277, 295, 572 bp.

Figure 5. Electrophoregram of digestion of $812 \mathrm{bp}$ PCR product (SCD-VII) with the $B c c I$ enzyme

In the 3 'UTR region of the SDC, the mutation $\mathrm{c} .{ }^{*} 1116 \mathrm{~A}>\mathrm{G}$ was identified (g.2044274A $>$ G, rs428791781). The RsaI enzyme was used to detect mutations in the animals (Figure 6). The frequency of individual alleles and genotypes for the studied breed populations is shown in Table 9. In meat-purpose breeds, i.e. Ile de France and Suffolk, a high frequency of the $\mathrm{G}$ allele -0.70 and 0.68 respectively - was recorded. High frequencies of the A allele were found in the case of Olkuska sheep (0.90) and Polish Mountain Sheep (0.85) breeds. In meat breeds and in the Kołuda sheep all three possible genotypes were identified. The frequency of the GG genotype in the Suffolk and Ile de France breeds was, respectively, $0.46(\mathrm{P}<0.01)$ 
and $0.49(\mathrm{P}<0.01)$, while for the Kołuda breed it was $0.22(\mathrm{P}<0.01)$. The populations of the individual breeds studied were in Hardy-Weinberg equilibrium in the analysed locus.

Table 9. Alleles and genotypes frequency at the locus c.*1116A>G

\begin{tabular}{l|c|c|c|c|c|c|c}
\hline \multirow{2}{*}{\multicolumn{1}{c}{ Breed }} & \multicolumn{7}{c}{ Alleles and genotypes frequency } \\
\cline { 2 - 8 } & Allele A & Allele G & AA & AG & GG & $\chi^{2}$ & P-value \\
\hline Ile de France & 0.30 & 0.70 & 0.09 & 0.42 & 0.49 & 0.37 & 0.54 \\
Suffolk & 0.32 & 0.68 & 0.10 & 0.44 & 0.46 & 0.99 & 0.99 \\
Kołuda sheep & 0.53 & 0.47 & 0.28 & 0.50 & 0.22 & 1.20 & 0.28 \\
Olkuska sheep & 0.90 & 0.10 & 0.81 & 0.19 & - & 0.19 & 0.54 \\
Polish Mountain Sheep & 0.85 & 0.15 & 0.72 & 0.28 & - & 0.60 & 0.33 \\
Population (n=150) & 0.58 & 0.42 & 0.33 & 0.49 & 0.18 & - & - \\
\hline
\end{tabular}

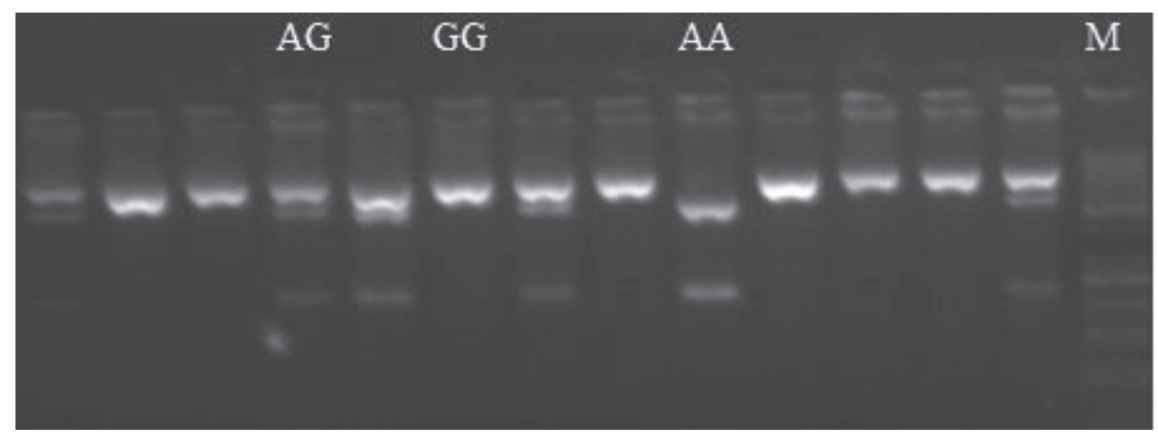

M - Gene Ruler 50 bp DNA Ladder \#SM0371 (Fermentas, Thermo Fisher Scientific, Waltham, Massachusetts, USA).

genotype AA - fragments of 237,575 bp in size.

genotype $\mathrm{AG}$ - fragments of $237,575,812 \mathrm{bp}$ in size.

genotype $\mathrm{GG}$ - fragments of 812 bp in size.

Figure 6. Electrophoregram of digestion of 812 bp PCR product (SCD-VII) with the Rsal enzyme

\section{Discussion}

The analysis of genetic variability in the FABP4 gene performed on 150 ewes belonging to five different sheep breeds allowed us to identify only two polymorphisms: c. $73+13 \mathrm{~A}>\mathrm{T}$ and c. $348+85 \mathrm{G}>\mathrm{A}$.

The presence of the identified c. $73+13 \mathrm{~A}>\mathrm{T}$ polymorphism was also noted for Moroccan sheep - as SNP g.57540957T >A - in the framework of the NextGen project, which aimed to study the biodiversity of livestock (cattle, sheep and goats) (http://projects.ensembl.org/nextgen/). The study performed on 160 individuals of 
Moroccan sheep also confirmed a high frequency of the A allele (0.93) - the same characteristic found in the breeds studied in Poland. Researchers involved in the NextGen project found a high frequency of wild-type AA homozygotes $(0.86)$ and a very low share of TT homozygotes with the mutation $(0.01)$. The results presented in this study show a similar allele distribution. However, compared to Moroccan sheep, a lower frequency of the AA genotype (0.74) and a higher incidence of AT individuals $(0.24)$ were noted. The frequency of wild-type homozygotes and heterozygotes in the Suffolk breed, in which all three genotypes were observed, differed markedly from the frequency of these genotypes reported for the studied Moroccan sheep breed.

The polymorphism c. $348+85 \mathrm{G}>\mathrm{A}(\mathrm{g} .57536954 \mathrm{C}>\mathrm{T})$ identified in the studied breeds in the FABP4 gene has also been demonstrated in Moroccan sheep as part of the NextGen project (http://projects.ensembl.org/nextgen/). The NextGen project researchers found a high frequency of the G allele (0.93) and the GG genotype (0.86), with a very low frequency of the AA genotype (0.01). In comparison, for the sheep population analysed in the presented Polish study, a lower frequency of the $G$ allele $(0.85)$ as well as of the wild-type GG homozygotes $(0.72)$ were observed, together with a higher frequency of the GA genotype (0.26). The presence of all three genotypes was demonstrated for the Polish Mountain Sheep and Suffolk breeds. However, the recorded genotype frequencies differed from those found in Moroccan sheep of the NextGen project.

Variation in the FABP4 gene in the sheep genome has not been given sufficient attention thus far, and the influence of polymorphism on quantitative traits has also not been analysed. One of the few described mutations is the substitution in intron 1 described as $209 \mathrm{~A}>\mathrm{G}$, which determines the quality of lamb meat in the Han, Tan and Inner Mongolia sheep breeds. Meat from individuals with the AA genotype is characterized by lower intramuscular fat content and better tenderness and marbling parameters (Xu et al., 2011). In introns 2 and 3, and exons 2 and 3, Yan et al. (2012) found eight mutations and identified 14 haplotypes occurring in animals belonging to eight different sheep breeds (Yan et al., 2012). Also, the analysis of genetic variability in two fragments of the FABP4 encoding gene in Barki sheep allowed the identification of the presence of two alleles $\left(\mathrm{A}_{1}, \mathrm{~A}_{2}\right)$ and three genotypes in the regions of exon 2 and intron 2, and four alleles $\left(\mathrm{B}_{1}, \mathrm{~B}_{2}, \mathrm{~B}_{3}, \mathrm{~B}_{4}\right)$ forming eight genotypes in the regions of exon 3 and intron 3 . It was shown that the genotypes defined for the first examined fragment affect meat $\mathrm{pH}$ and percentage share of shoulder in the lamb carcass. In contrast, the genotypes identified for the fragment in the region of exon 3 and intron 3 impacted the values of such parameters as body mass, percentage share of fat and meat in the lamb carcass (Ibrahim et al., 2014).

In the non-coding regions of the PPAR $\gamma$ gene, two mutations were identified: c. $391-66 \mathrm{C}>\mathrm{T}(\mathrm{c} .481-66 \mathrm{C}>\mathrm{T})$ in intron 3 and c. $529+27 \mathrm{G}>\mathrm{C}(\mathrm{c} .619+27 \mathrm{G}>\mathrm{C})$ in intron 4. It should be emphasized that despite the frequency of the $\mathrm{T}$ and $\mathrm{C}$ alleles recorded in the experiment presented here (at loci c.391-66C>T and c.529+ $27 \mathrm{G}>\mathrm{C}$ ), pointing to them as being wild-type alleles, both polymorphisms referred to in this paper are in accordance with the nomenclature of the NCBI database (NextGen project). 
The mutations identified in the PPAR $\gamma$ gene sequence in domestic breeds have so far been identified only in a small population of Iranian and Moroccan sheep. Work on understanding the sheep genome as part of the NextGen project (http://projects. ensembl.org/nextgen/) showed that the population of Iranian sheep was monomorphic (TT genotype) in the c.391-66C>T locus. In the case of Moroccan sheep, the $\mathrm{T}$ allele occurred at a frequency of 0.93 . The highest incidence was shown for TT homozygotes (0.86) and the lowest for the CC genotype (0.01). In our studies, the presence of only TT homozygotes was found in ewes of the prolific dairy breeds with mixed dairy/meat body constitutions - Kołuda and Olkuska sheep. All three genotypes were identified only in the population of the Ile de France meat breed. However, it was found that in this breed, the allele and genotype distribution differed from those recorded for Moroccan sheep. For the other breeds studied as part of our research in Poland, the frequency of alleles and genotypes was similar to those reported in Moroccan sheep.

In the case of the polymorphism c. $529+27 \mathrm{G}>\mathrm{C}(\mathrm{c} .619+27 \mathrm{G}>\mathrm{C})$, a similarity can be observed between allele and genotype frequency in the breeds raised in Poland and the results obtained in Moroccan sheep under the NextGen project. In the case of breeds of the mixed dairy/meat body constitution - Kołuda and Olkuska sheep - similarly as for Iranian sheep, only the CC genotype was identified. In Moroccan sheep, a higher frequency was recorded for the $\mathrm{C}$ allele $(0.93)$, and the $\mathrm{CC}$ (0.86) and GC (0.13) genotypes. It should be stressed that all three genotypes were present only in ewes of the Ile de France meat breed (strong, muscular physique with high fat content), but the distribution of alleles and genotypes differed from that reported for Moroccan sheep.

The analysis of variability in the $S C D$ gene structure of Polish sheep breeds allowed us to identify two mutations: c. ${ }^{* 945 G}>$ A $($ g. $20442503 \mathrm{C}>\mathrm{T})$ and c. ${ }^{* 1116 A}>\mathrm{G}$ (g.2044274A > G).

The mutation c. ${ }^{*} 945 \mathrm{G}>\mathrm{A}$ is a SNP at position 2218 in the 5 '-UTR region. It is a mutation whose presence has been demonstrated and confirmed in Ovis aries for the very first time, although it should be noted that the GA heterozygous genotype was identified only in one animal of the Suffolk meat breed. The frequency of the G allele among the experimental animals was 0.99 .

The distribution of genotypes for the locus $c{ }^{*} 1116 \mathrm{~A}>\mathrm{G}$ identified in our own studies for all five breeds tested in Poland was similar to that obtained for the Iranian and Moroccan sheep of the NextGen project (http://projects.ensembl.org/nextgen/). Project researchers found the presence of three genotypes, with the highest frequencies recorded for the AA ( 0.55 for Iranian and 0.29 for Moroccan sheep) and AG ( 0.30 and 0.52$)$ genotypes; the A allele frequency was 0.70 and 0.55 respectively for these breeds.

Analysis of the coding sequence of the $S C D$ gene in meat breeds (Berrichon du Cher, Ojalada), dairy (Assaf, Castellana, Churra, Lacaune) and primitive (Ossimi, Rahmani) sheep breeds from Spain, France, Israel and Egypt did not demonstrate the presence of mutations (García-Fernández et al., 2009). Lack of changes in the coding region sequence may suggest that the fatty acid profile in sheep is dependent on mutations occurring at the binding sites of elements regulating the expression of 
stearoyl-CoA desaturase. The polymorphisms detected in sheep in the 3'-UTR region may serve as confirmation of this assumption (Bernard et al., 2001; García-Fernández et al., 2009). Four SNPs were identified in the non-coding region of $S C D$ in sheep: g.31C $>$ A (SCD01) in the promoter region, g.1473A $>$ G (SCD02) and g.2011T $>C$ (SCD03) in intron 2 and g.2893G $>$ A (SCD04) in intron 3. In testing performed on eight sheep breeds, it was shown that the greatest variation occurs in the case of the SCD01 mutation. Greater genetic diversity was observed for dairy breeds compared to meat breeds. Due to the fact that this mutation is more common in dairy breeds, it is assumed that it affects the content and profile of fatty acids in milk, and may also affect lipid synthesis in the mammary gland. It has also been shown that the g.31C $>\mathrm{A}$ mutation (SCD01) may affect regulatory elements in desaturase expression (GarcíaFernández et al., 2009).

In our opinion, only for SNP c. ${ }^{*} 1116 \mathrm{~A}>\mathrm{G}$ in $S C D$ gene, the probable relationship between polymorphism and the sheep usage type exist. The high frequency of the $\mathrm{G}$ allele in meat breed ewes in comparison to prolific dairy and primitive breeds may affect slaughter value parameters and is associated with sheep body shape (breeding purpose - meat vs. dairy). Additional studies should be carried out to confirm the effect of this mutation on meat quality traits in Suffolk and the Ile de France breeds. Demonstration of the possible influence of the c. ${ }^{*} 1116 \mathrm{~A}>\mathrm{G}$ polymorphism on growth rate, slaughter value parameters and quality of lamb meat may serve to justify the selection of farm animals by considering the desired genotype in the examined locus.

To summarize, six polymorphisms were identified in our study of the genetic structure in the regions of coding and regulatory sequences and splice sites of the $F A B P 4, P P A R \gamma$ and $S C D$ genes in five sheep breeds raised for different purposes: meat breeds (Suffolk, Ile de France), prolific dairy (Olkuska, Kołuda) and primitive (Polish Mountain Sheep). The c. ${ }^{* 945 G}>$ A mutation was identified in Ovis aries and described for the first time as part of the presented study. It should be emphasized that only the single nucleotide polymorphism c. ${ }^{*} 1116 \mathrm{~A}>\mathrm{G}$ showed a possible correlation with the sheep body type and breed usage type (dairy or meat) of the studied sheep.

\section{References}

Ari y a ma H., K on o N., Mats u d a S., In o u e T., A r a i H. (2010). Decrease in membrane phospholipid unsaturation induces unfolded protein response. J. Biol. Chem., 285: 22027-22035.

Barak Y., Nelson M.C., Ong E.S., Jones Y.Z., Ruiz-Lozano P., Chien K.R., Kod e r A., E v a n s R.M. (1999). PPAR $\gamma$ is required for placental, cardiac, and adipose tissue development. Mol. Cell, 4: 585-595.

B a rbi ero J.K., S antiago R.M., Persike D.S., da Silva Fernandes M.J., Tonin F.S., da Cunha C., Lucio Bos chen S., Lima M.M.S., Vital M.A.B.F. (2014). Neuroprotective effects of peroxisome proliferator-activated receptor alpha and gamma agonists in model of parkinsonism induced by intranigral 1-methyl-4-phenyl-1,2,3,6-tetrahyropyridine. Behav. Brain Res., 274: 390-399.

B ernard L., Leroux C., Hayes H., Gautier M., Chilliard Y., Martin P. (2001). Characterization of the caprine stearoyl-CoA desaturase gene and its mRNA showing an unusually long 3'-UTR sequence arising from a single exon. Gene, 281: 53-61. 
Cao H., Gerhold K., Mayers J.R., Wiest M.M., Watkins S.M., Hotamis ligil G.S. (2008). Identification of a lipokine, a lipid hormone linking adipose tissue to systemic metabolism. Cell, 134: 933-944.

Corl B.A., B a u m gard L.H., Dw y e r D.A., Gri in ari J.M., Phillips B.S., B a u m a D.E. (2001). The role of $\Delta 9$-desaturase in the production of cis-9, trans-11 CLA. J. Nutr. Biochem., 12: $622-630$.

D ix on J.L., F u ruk a w a S., G in s b e r g H.N. (1991). Oleate stimulates secretion of apolipoprotein B-containing lipoproteins from Hep G2 cells by inhibiting early intracellular degradation of apolipoprotein B. J. Biol. Chem., 266: 5080-5086.

En o ch H.G., Catala A., Stritt matter P. (1976). Mechanism of rat liver microsomal stearylCoA desaturase. Studies of the substrate specificity, enzyme-substrate interactions, and the function of lipid. J. Biol. Chem., 251: 5095-5103.

F a n Y.Y., Z an L.S., F u C.Z., Ti an W.Q., Wang H.B., L i u Y.Y., X in Y.P. (2011). Three novel SNPs in the coding region of PPAR $\gamma$ gene and their associations with meat quality traits in cattle. Mol. Biol. Rep., 38: 131-137.

F a n Y.Y., F u G.W., F u C.Z., Z a n L.S., T i a n W.Q. (2012). A missense mutant of the PPAR-gamma gene associated with carcass and meat quality traits in Chinese cattle breeds. Genet. Mol. Res., 11: 3781-3788.

F e r r e P. (2004). The biology of peroxisome proliferators-activated receptors. Diabetes, 53: 43-50.

F u Y., L u o N., L o pe s - Vir e 11 a M.F. (2000). Oxidized LDL induces the expression of ALBP/aP2 mRNA and protein in human THP-1 macrophages. J. Lipid Res., 41: 2017-2023.

García-Fernández M., Gutiérrez-Gil B., García-Gámez E., Arranz J.J. (2009). Genetic variability of the stearoyl-CoA desaturase gene in sheep. Mol. Cell. Probe., 23, 107-111.

Gutiérrez-Juárez R., Pocai A., Mulas C., Ono H., B hanot S., Monia B.P., Rosset t $\mathrm{i}$ L. (2006). Critical role of stearoyl-CoA desaturase-1 (SCD1) in the onset of diet-induced hepatic insulin resistance. J. Clin. Invest., 116: 1686-1695.

$\mathrm{H}$ a $\mathrm{n}$ h off T., L ü c k e C., S p e n e r F. (2002). Insights into binding of fatty acids by fatty acid binding proteins. Mol. Cell. Biochem., 239: 45-54.

I b r a h i m A.H.M., S he hat a M.F., I s ma il I.M., G a d S.M.A. (2014). Association of fatty acid binding protein 4 (FABP4) polymorphisms with growth and carcass traits of Barki sheep. J. Am. Sci., 10: 10-15.

Jiang Y., Xie M., Chen W., Talbot R., Maddox J.F., Faraut T., Wu C., Muzny D.M., Li Y., Zhang W., S t a n to n J.A., Brauning R., B arris W.C., Hourli er T., A ken B.L., S e a rle S.M., A dels on D.L., B i n C., Cam G.R., Chen Y., Cheng S., De Silva U., Dixen K., Dong Y., F an G., Franklin I.R., Fu S., Fuentes-Utrilla P., Guan R., H i g h l a nd M.A., Hold e r M.E., Hu ang G., Ingham A.B., Jh an gi a n i S.N., K a l r a D., Kovar C.L., L e e S.L., Liu W., Liu X., Lu C., Lv T., Mathew T., McWilliam S., Menzies M., Pan S., Robelin D., Servin B., Townley D., Wang W., Wei B., White S.N., Yang X., Ye C., Yue Y., Zeng P., Zhou Q., Hansen J.B., Kristians en K., Gibbs R.A., Flicek P., Warkup C.C., Jones H.E., Oddy V.H., Nicholas F.W., McEwan J.C., Kij a s J.W., Wang J., Worley K.C., A r chibald A.L., C ock e t t N., X u X., Dalry m ple B.P. (2014). The sheep genome illuminates biology of the rumen and lipid metabolism. Science, 344: 1168-1173.

Karahashi M., Ishii F., Yamazaki T., Imai K., Mitsumoto A., Kawashima Y., K udo N. (2013). Up-regulation of stearoyl-CoA desaturase 1 increases liver MUFA content in obese zucker but not Goto-Kakizaki rats. Lipids, 48: 457-467.

Kersten S., S ey doux J., P eters J.M., Gonzalez F.J., D e s vergne B., Wahli W. (1999). Peroxisome proliferator-activated receptor alpha mediates the adaptive response to fasting. J. Clin. Invest., 103: 1489-1498.

Koutnikova H., Cock T.A., Wat a nabe M., Houten S.M., Champy M.F., Di erich A., A u w e r x J. (2003). Compensation by the muscle limits the metabolic consequences of lipodystrophy in PPAR gamma hypomorphic mice. P. Natl. Acad. Sci. USA, 100: 14457-14462.

Le grand P., Catheline D., F i chot M., L e mar chal P. (1997). Inhibiting D9-desaturase activity impairs triacylglycerol secretion in cultured chicken hepatocytes. J. Nutr., 127: 249-256.

Mari o n-L e t e 11 i e r R., S a v o y e G., G ho s h S. (2015). Fatty acids, eicosanoids and PPAR gamma. Eur. J. Pharmacol., 795: 44-49. 
M a t a r e s e V., B e r $\mathrm{n}$ l o h r D.A. (1988). Purification of murine adipocyte lipid-binding protein. Characterization as a fatty acid- and retinoic acid-binding protein. J. Biol. Chem., 263: 14544-14551.

Mish kin S., S te in L., Gat ma it a n Z., A ri a s I.M. (1972). The binding of fatty acids to cytoplasmic proteins: Binding to $\mathrm{Z}$ protein in liver and other tissues of the rat. Biochem. Bioph. Res. Co., 47: 997-1003.

Mi y a za ki M., K i m Y.C., Gra y - K e 11 e r M.P., A t t i e A.D., N t a m b i J.M. (2000). The biosynthesis of hepatic cholesterol esters and triglycerides is impaired in mice with a disruption of the gene for stearoyl-CoA desaturase 1. J. Biol. Chem., 275: 30132-30138.

Niżnikowski R. (2011). Sheep breeding, rearing and use (in Polish). Wieś Jutra, Warszawa, pp. 21-32.

N ta mbi J.M., Miyazaki M., D obrzyn A. (2004). Regulation of stearoyl-CoA desaturase expression. Lipids, 39: 1061-1065.

O c kner R.K., Manning J.A., P op penhausen R.B., Ho W.K. (1972). A binding protein for fatty acids in cytosol of intestinal mucosa, liver, myocardium, and other tissues. Science, 177: 56-58.

P is anu A., L e c c a D., Mula s G., Ward as J., S i mbula G., S piga S., Carta A.R. (2014). Dynamic changes in pro- and anti-inflammatory cytokines in microglia after PPAR- $\gamma$ agonist neuroprotective treatment in the MPTPp mouse model of progressive Parkinson's disease. Neurobiol. Dis., 71: 280-291.

Ros en E.D., S arraf P., Troy A.E., Bradwin G., Moore K., Mils ton e D.S., S pi e ge lm a n B.M., M o r t e n s e n R.M. (1999). PPAR gamma is required for the differentiation of adipose tissue in vivo and in vitro. Mol. Cell, 4: 611-617.

Sevane N., Armstrong E., Cortés O., Wi ener P., Wong R.P., Dunner S. (2013). Association of bovine meat quality traits with genes included in the PPARG and PPARGC1A networks. Meat Sci., 94: 328-335.

S obrado M., P ereir a M.P., B a lles teros I., Hurtado O., F ernández - Ló pe z D., Pra dillo J.M., Cas o J.R., Vivancos J., Moro M.A. (2009). Synthesis of lipoxin A 4 by 5-lipoxygenase mediates PPAR $\gamma$-dependent, neuroprotective effects of rosiglitazone in experimental stroke. J. Neurosci., 29: 3875-3884.

Tontonoz P., Hu E., Graves R.A., Budavari AI., S pi e g e 1 man B.M. (1994). mPPARgamma2: Tissue-specific regulator of an adipocyte enhancer. Gene. Dev., 8: 1224-1234.

We i Y., Wang D., T o p c ze w s k i F., P a g li a s s o t t i M.J. (2006). Saturated fatty acids induce endoplasmic reticulum stress and apoptosis independently of ceramide in liver cells. Am. J. Physiol.Endoc. M., 291: 275-281.

We i Y., Wang D., Gentile C.L., Paglias s otti M.J. (2009). Reduced endoplasmic reticulum luminal calcium links saturated fatty acid-mediated endoplasmic reticulum stress and cell death in liver cells. Mol. Cell. Biochem., 331: 31-40.

Will s o n T.M., B row n P.J., S t e r n b a ch D.D., H e n k e B.R. (2000). The PPARs: From orphan receptors to drug discovery. J. Med. Chem., 43: 527-550.

X u Q.L., Tang G.W., Z hang Q.L., H u ang Y.K., L i u Y.X., Qu a n K., Z hu K.Y., Zhang C.X. (2011). The FABP4 gene polymorphism is associated with meat tenderness in three Chinese native sheep breeds. Czech J. Anim. Sci., 56: 1-6.

Yan W., Z h o u H., L u o Y., H u J., H i c kford J.G.H. (2012). Allelic variation in ovine fatty acidbinding protein (FABP4) gene. Mol. Biol. Rep., 39: 10621-10625.

Yeh F.C., B o y le J. (1997). POPGENE, the user-friendly shareware for population genetic analysis. Mol. Biol. Biotechnol., 434: 724-731.

Zha o Y., Calon F., Julien C., Winkler J.W., P e tas is N.A., Lukiw W.J., B a zan N.G. (2011). Docosahexaenoic acid-derived neuroprotectin D1 induces neuronal survival via secretase- and PPAR $\gamma$-mediated mechanisms in Alzheimer's disease models. PLoS ONE, 6. http://doi. org/10.1371/journal.pone.0015816

Z i m m erm a n A.W., Ve er k a m p J.H. (2002). New insights into the structure and function of fatty acid-binding proteins. Cell. Mol. Life Sci.: CMLS, 59: 1096-1116. 